\title{
Greater tau load and reduced cortical thickness in APOE \&4-negative Alzheimer's disease: a cohort study
}

\author{
Niklas Mattsson ${ }^{1,2^{*}+}$, Rik Ossenkoppele ${ }^{1,3+}$, Ruben Smith ${ }^{1,3}$, Olof Strandberg ${ }^{1}$, Tomas Ohlsson ${ }^{4}$, Jonas Jögi ${ }^{5}$, \\ Sebastian Palmqvist ${ }^{1,2}$, Erik Stomrud ${ }^{1}$ and Oskar Hansson ${ }^{1,6}$
}

\begin{abstract}
Background: Alzheimer's disease is characterized by aggregated $\beta$-amyloid and tau proteins, but the clinical presentations and patterns of brain atrophy vary substantially. A part of this heterogeneity may be linked to the risk allele $A P O E \varepsilon 4$. The spread of tau pathology is related to atrophy and cognitive decline, but little data exist on the effects of $A P O E \varepsilon 4$ on tau. The objective of this preliminary study was therefore to test if tau load and brain structure differ by APOE $\varepsilon 4$ in Alzheimer's disease.

Methods: Sixty-five $\beta$-amyloid-positive patients at the prodromal and dementia stages of Alzheimer's disease were enrolled, including APOE \&4-positive $(n=46)$ and APOE $\varepsilon 4$-negative $(n=19)$ patients. ${ }^{18} \mathrm{~F}$-AV-1451 positron emission tomography was used to measure tau and brain magnetic resonance imaging (MRI) was used to measure cortical thickness.

Results: Compared with their APOE \&4-positive counterparts, APOE \&4-negative patients had greater tau load and reduced cortical thickness, with the most pronounced effects for both in the parietal cortex. Relative to the overall cortical tau load, APOE \&4-positive patients had greater tau load in the entorhinal cortex. APOE $\varepsilon 4$-positive patients also had slightly greater cortical $\beta$-amyloid load. There was an interaction between APOE $\varepsilon 4$ and ${ }^{18} \mathrm{~F}-\mathrm{AV}-1451$ on cortical thickness, with greater effects of ${ }^{18} \mathrm{~F}$-AV-1451 on cortical thickness in APOE $\varepsilon 4$-negative patients. APOE $\varepsilon 4$ and ${ }^{18} \mathrm{~F}$-AV-1451 were independent predictors of cognition, but showed distinct associations with different cognitive tests.

Conclusions: APOE genotype may be associated with differences in pathways in Alzheimer's disease, potentially through differential development and spread of tau, as well as through effects on cognitive outcomes involving non-tau-related mechanisms.
\end{abstract}

Keywords: APOE, Tau, Atrophy, Cognition, Alzheimer's disease

\section{Background}

Most Alzheimer's disease (AD) patients have an amne stic-predominant cognitive impairment profile, while others have more prominent executive, language, or visuospatial deficits [1, 2]. The variations in presentations may be associated with specific patterns of neurodegeneration

\footnotetext{
* Correspondence: Niklas.mattsson@med.lu.se

${ }^{+}$Niklas Mattsson and Rik Ossenkoppele contributed equally to this work.

${ }^{1}$ Clinical Memory Research Unit, Department of Clinical Sciences, Faculty of Medicine, Lund University, Lund, Sweden

2Department of Neurology, Skåne University Hospital, Lund University, Lund, Sweden

Full list of author information is available at the end of the article
}

or tau pathology [3-6], but the reason why the regional involvement of neurodegeneration and tau varies is largely unclear [7]. One possibility is that the apolipoprotein $(A P O E) \varepsilon 4$ allele contributes to the variability. $A P O E \varepsilon 4$ is a major genetic risk factor for sporadic $\mathrm{AD}$, and is present in $50-70 \%$ of patients [8-10]. However, roughly a third of all $\mathrm{AD}$ patients develop the disease without carrying an $A P O E$ $\varepsilon 4$ allele. $A P O E$ \&4-negative patients are characterized by relatively more nonamnestic deficits and anatomically by greater frontoparietal atrophy, while $A P O E$ \&4-positive patients predominantly demonstrate memory impairment and temporal lobe atrophy [11-15]. Given the intimate link

(C) The Author(s). 2018 Open Access This article is distributed under the terms of the Creative Commons Attribution 4.0 International License (http://creativecommons.org/licenses/by/4.0/), which permits unrestricted use, distribution, and 
between tau pathology and neurodegeneration in neuroimaging [3, 16-19], neuropathology [20], and cell and animal studies [21], it is possible that $A P O E \& 4$ status affects the spread of tau in $\mathrm{AD}$ and subsequent brain atrophy, but only few studies have explored this [22-24]. We tested if APOE $\varepsilon 4$ was associated with regional and global differences in ${ }^{18} \mathrm{~F}-\mathrm{AV}-1451$ in prodromal AD and AD dementia patients, and if $A P O E$ \&4 status and ${ }^{18} \mathrm{~F}-\mathrm{AV}-1451$ interacted to predict atrophy and cognition. We hypothesized that $A P O E$ $\varepsilon 4$-positive patients would have more tau pathology and atrophy in the temporal lobe, while $A P O E$ \&4-negative patients would be more affected by tau and atrophy in other brain regions, in particular the frontal and parietal areas.

\section{Methods}

\section{Participants}

All participants were recruited from the Swedish BioFINDER study. Inclusion and exclusion criteria have been described previously [25]. We included prodromal $\mathrm{AD}$ (amyloid- $\beta$ (A $\beta$ )-positive mild cognitive impairment $[\mathrm{MCI}]$ ) [26] and mild-to-moderate (A $\beta$-positive) AD dementia patients who were all assessed by physicians with expertise in dementia. A $\beta$-positivity was defined by cerebrospinal fluid (CSF) A $\beta 42$ in all cases except one for whom ${ }^{18} \mathrm{~F}$-flutemetamol positron emission tomography (PET) was used. The inclusion criteria for MCI were: referred to a memory clinic due to possible cognitive impairment; objective impairment in one or more cognitive domains; preservation of independence in functional abilities; and not fulfilling criteria for any dementia disorder. All dementia patients met the NIA-AA criteria for dementia due to AD [27]. The exclusion criteria were: cognitive impairment that without doubt could be explained by another condition other than prodromal AD or AD dementia; significant systemic illness making it difficult to participate; and significant alcohol or drug abuse.

\section{Cognitive measures}

Cognitive measures included Mini-Mental State Examination (MMSE) [28] for global cognition, the immediate and delayed conditions of the 10-word list recall tests from the Alzheimer's Disease Assessment Scale (ADAS)-cognitive subscale [29] for memory, Trail Making Test-A (TMT-A) [30], and A Quick Test of cognitive speed-Color \& Form subtest (AQT-CF) [31] for attention and processing speed, and category fluency [30] for language and semantic memory (animal fluency) and executive function (letter S fluency). Data were missing for MMSE in one subject, for ADAS immediate recall in six subjects, for ADAS delayed recall in seven subjects, for TMT-A in nine subjects, for letter S fluency and animal fluency in 12 subjects, and for AQT-CF in 14 subjects. The reason for missing cognitive data was either refusal or cognitive inability to perform the task. We kept all eligible subjects for this analysis, even if they lacked some cognitive data, since exclusion based on missing data would have increased the risk of a selection bias.

\section{CSF biomarkers}

Lumbar CSF sampling was performed following the Alzheimer's Association Flow Chart [32]. Samples were stored in $1-\mathrm{ml}$ polypropylene tubes at $-80{ }^{\circ} \mathrm{C}$ until analysis. Enzyme-linked immunosorbent assays (ELISAs) were used for CSF A $\beta 42$, total (T)-tau, and phosphorylated (P)-tau (ADx/Euroimmun AG, Lübeck, Germany, and Innotest, Fujirebio, Ghent, Belgium). All analyses were performed by board-certified laboratory technicians who were blinded for clinical data and diagnoses. A $\beta$-positivity was defined as CSF A $\beta 42<647 \mathrm{ng} / \mathrm{L}$ [33]. For one subject who refused to undergo lumbar puncture we determined $\mathrm{A} \beta$-positivity by ${ }^{18} \mathrm{~F}$-flutemetamol PET (see below for details).

\section{Magnetic resonance imaging (MRI)}

T1-weighted MRI was performed on a 3-T MR scanner in all subjects (Siemens Tim Trio 3 T, Siemens Medical Solutions, Erlangen, Germany), producing a high resolution anatomical MP-RAGE image $(\mathrm{TR}=1950 \mathrm{~ms}, \mathrm{TE}=3.4$ $\mathrm{ms}, 1 \mathrm{~mm}$ isotropic voxels, and 178 slices). Cortical reconstruction and volumetric segmentation were performed with FreeSurfer (v5.3) (http://surfer.nmr.mgh.harvard.edu/) using an in-house developed image analysis pipeline. The MP-RAGE images underwent correction for intensity homogeneity [34], removal of nonbrain tissue, and segmentation into gray matter (GM) and white matter (WM) with intensity gradient and connectivity among voxels [35-38]. Cortical thickness was measured as the distance from the GM/WM boundary to the corresponding pial surface [36]. Reconstructed datasets were visually inspected for accuracy, and segmentation errors were corrected. The surface area-weighted average cortical thickness was calculated for seven FreeSurfer-based metaregions: lateral parietal, medial parietal, lateral temporal, medial temporal, frontal, occipital, and whole brain cortex (Additional file 1: Table S1). We also calculated the ratio between entorhinal cortical thickness and overall cortical thickness in accordance with Whitwell et al. [24] (E/C ratio, the overall cortical region included the whole cortex except for entorhinal and the inferior temporal gyri, since tau accumulation there may be closely linked to entorhinal tau).

Automated segmentation of white matter lesions (WML) was performed using the lesion prediction algorithm as implemented in the LST toolbox (www.statistical-modelling.de/lst.html) for SPM. This algorithm consists of a binary classifier in the form of a logistic regression model; as covariates, a lesion belief map [39] is used as well as a spatial covariate that takes into account voxel-specific changes in lesion probability. Parameters 
Table 1 Patient characteristics

\begin{tabular}{|c|c|c|c|}
\hline & $\begin{array}{l}\text { APOE \&4-negative } \\
(n=19)\end{array}$ & $\begin{array}{l}\text { APOE \&4-positive } \\
(n=46)\end{array}$ & $P$ value \\
\hline Diagnosis, $n$ (MCl due to AD/AD dementia) & $4 / 15$ & $18 / 28$ & 0.27 \\
\hline Age (years) & $70.1 \pm 7.8$ & $72.4 \pm 6.8$ & 0.23 \\
\hline Sex, $n$ (male/female) & $9 / 10$ & $18 / 28$ & 0.29 \\
\hline Education, years & $11.1 \pm 2.7$ & $12.5 \pm 3.4$ & 0.13 \\
\hline APOE genotype & $\varepsilon 3 / \varepsilon 3(n=19)$ & $\begin{array}{l}\varepsilon 2 / \varepsilon 4(n=3) \\
\varepsilon 3 / \varepsilon 4(n=27) \\
\varepsilon 4 / \varepsilon 4(n=16)\end{array}$ & NA \\
\hline CSF A $\beta 42, \mathrm{ng} / \mathrm{L}$ & $405 \pm 97$ & $405 \pm 104$ & 0.99 \\
\hline CSF T-tau, ng/L & $855 \pm 366$ & $673 \pm 283$ & 0.035 \\
\hline CSF P-tau, ng/L & $105 \pm 4$ & $81 \pm 31$ & 0.012 \\
\hline WML, mL & $15.5(13.8)$ & $11.9(14.0)$ & 0.31 \\
\hline Hippocampal volume, $\mathrm{mL}$ & $2968(576)$ & $2907(442)$ & 0.50 \\
\hline MMSE & $22.2 \pm 5.8$ & $22.6 \pm 4.3$ & 0.73 \\
\hline ADAS immediate recall & $5.9 \pm 1.8$ & $5.9 \pm 1.3$ & 0.98 \\
\hline ADAS delayed recall & $6.2 \pm 3.1$ & $8.0 \pm 2.01$ & 0.018 \\
\hline TMT-A & $123.6 \pm 112.0$ & $75.0 \pm 42.5$ & 0.021 \\
\hline AQT-CF & $102.9 \pm 27.6$ & $91.2 \pm 38.5$ & 0.35 \\
\hline Fluency_animals & $9.9 \pm 6.8$ & $12.1 \pm 5.2$ & 0.21 \\
\hline Fluency-letter (S) & $8.0 \pm 5.6$ & $11.1 \pm 4.9$ & 0.055 \\
\hline
\end{tabular}

of this model fit are used to segment lesions by providing an estimate for the lesion probability for each voxel.

\section{${ }^{18} \mathrm{~F}-\mathrm{AV}-1451$ tau PET imaging and processing}

Tau PET was performed in all subjects as described previously [40]. Briefly, ${ }^{18} \mathrm{~F}-\mathrm{AV}-1451$ was synthesized at Skåne University Hospital, Lund [41], and PET scans were performed on a GE Discovery 690 PET scanner (General Electric Medical Systems). FreeSurfer parcellation in the MR space of the anatomical scan was applied to processed, coregistered and time-averaged PET images to extract regional uptake values. ${ }^{18} \mathrm{~F}-\mathrm{AV}-1451$ standardized uptake value ratio (SUVr) images were based on mean uptake over 80-100 min postinjection normalized to uptake in a GM-masked inferior cerebellum reference region. The signal was not corrected for partial volume effects.

The same FreeSurfer metaregions as for MRI, including the $\mathrm{E} / \mathrm{C}$ ratio, were calculated for ${ }^{18} \mathrm{~F}-\mathrm{AV}-1451$ (volume weighted; Additional file 1: Table S1). We excluded the hippocampus from the medial temporal metaregion because of its susceptibility to spill-over effects from the anatomically proximate choroid plexus [40].

\section{${ }^{18}$ F-flutemetamol PET imaging}

Fibrillary brain $\mathrm{A} \beta$ was quantified in a subgroup $(n=54)$ using ${ }^{18}$ F-flutemetamol PET. PET/computed tomography (CT) scanning was conducted at two sites using the same type of scanner, a Philips Gemini TF 16. PET sum images from 90 to $110 \mathrm{~min}$ postinjection were generated for the average uptake. FreeSurfer parcellation in the MR space of the anatomical scan was applied to the processed images. The SUVr images were normalized to the mean uptake in a composite region consisting of cerebellar white matter, brainstem and cerebral white matter. We used the same FreeSurfer metaregions (volume weighted) as for ${ }^{18} \mathrm{~F}-\mathrm{AV}-1451$ and additionally assessed the striatum.

${ }^{18}$ F-flutemetamol PET SUVr in a composite neocortical region-of-interest indicated $A \beta$-positivity in one subject who refused to undergo lumbar puncture [42].

\section{Statistical analysis}

Statistical analyses were performed with R (v. 3.3.2, The $\mathrm{R}$ Foundation for Statistical Computing). The relationships between demographics and $A P O E \varepsilon 4$ were evaluated with Fisher's exact test and Wilcoxon-MannWhitney rank sum test. 


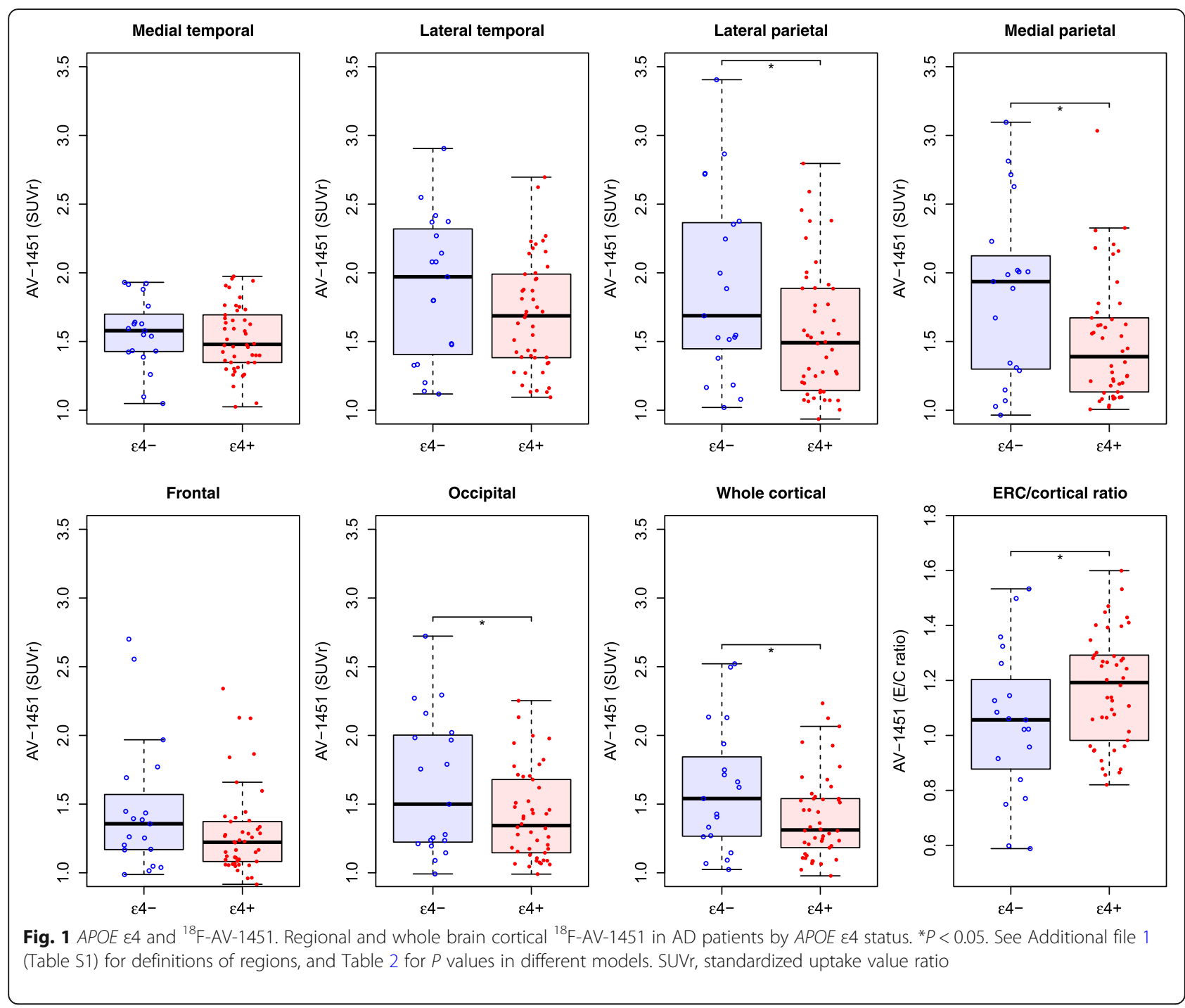

We used linear regression to test effects of $A P O E \varepsilon 4$ status on ${ }^{18} \mathrm{~F}$-AV-1451, ${ }^{18} \mathrm{~F}$-flutemetamol, cortical thickness, and interactions of APOE \&4 status and ${ }^{18} \mathrm{~F}-\mathrm{AV}-1451$ to predict cortical thickness and cognition. Covariates included age, sex, education, CSF A 342 , WML, and CSF P-tau.

In secondary analyses, we compared models for $A P O E$ $\varepsilon 4$ and ${ }^{18} \mathrm{~F}-\mathrm{AV}-1451$ to predict cognition, with and without adjusting for each other, to test if they provided independent information. We adjusted for brain MRI measures to test if effects of $A P O E \& 4$ and ${ }^{18} \mathrm{~F}-\mathrm{AV}-1451$ on cognition were independent of atrophy. Akaike Information Criterion (AIC) was used for model comparisons. Statistical significance was determined at $P<0.05$.

\section{Primary research question}

Does regional cortical thickness and ${ }^{18} \mathrm{~F}-\mathrm{AV}-1451$ PET uptake differ by $A P O E \& 4$ status in $\mathrm{AD}$ patients at the prodromal and dementia stage of the disease?

\section{Results}

We included 46 APOE $\varepsilon 4$-positive and 19 APOE $\varepsilon 4$-negative $A D$ patients, with no significant group differences regarding age, sex, education, WML, hippocampal volume, global cognition (MMSE), or CSF A 342 (Table 1). APOE \&4-negative patients had higher CSF T-tau $(P=0.035)$ and $P$-tau $(P=0.012)$, better memory function (the ADAS delayed recall, $P=0.018$ ), and worse executive function (TMT-A, $P=0.021$ ). Fifty-four patients (37 APOE \&4-positive and $17 A P O E$ \&4-negative) had ${ }^{18}$ F-flutemetamol PET data. The $A P O E$ \&4-positive patients had slightly greater $A \beta$ load (Additional file 1: Figure S1).

\section{Associations for APOE $\varepsilon 4$ with ${ }^{18}$ F-AV-1451 tau PET and cortical thickness}

$A P O E$ \&4-negative patients had greater ${ }^{18} \mathrm{~F}-\mathrm{AV}$-1451 uptake in lateral parietal, medial parietal, occipital, and whole brain cortical areas compared with $A P O E$ \&4-positive patients, 
while $A P O E$ \&4-positive patients had greater ${ }^{18} \mathrm{~F}-\mathrm{AV}$-1451 $\mathrm{E} / \mathrm{C}$ ratio uptake (Fig. 1). All differences remained significant when adjusting for CSF A 342 or WML, and differences in the medial parietal cortex also remained significant when adjusting for age and sex (Table 2 and Additional file 1: Table S2). When adjusting for CSF P-tau, effects remained significant in the medial parietal cortex, with trends for the lateral parietal cortex and $\mathrm{E} / \mathrm{C}$ ratio (Additional file 1: Table S2). APOE $\varepsilon 4$-negative patients also had thinner cortex in lateral and medial parietal areas compared with APOE \&4-positive patients (Fig. 2 and Table 2).

In a secondary analysis, we tested effects in the AD dementia subgroup only (15 APOE $\varepsilon 4$-negative and $28 A P O E$ $\varepsilon 4$-positive patients) to better account for differences in disease severity. APOE $\varepsilon 4$ status was not related to global cognition (MMSE (mean \pm SD) $20.9 \pm 5.7$ vs. $20.8 \pm 4.3$, $P=0.93)$ or age $(68.9 \pm 8.1$ vs. $72.1 \pm 7.9, P=0.18)$ in these patients, but $A P O E \varepsilon 4$-negative patients still had increased ${ }^{18} \mathrm{~F}-\mathrm{AV}-1451$ in the lateral and medial parietal and whole brain cortical areas (Additional file 1: Figure S2) and had thinner parietal cortices (Additional file 1: Figure S3).

\section{Interactions of APOE $\varepsilon 4$ and ${ }^{18} \mathrm{~F}-\mathrm{AV}$-1451 tau PET to predict cortical thickness}

Next, we tested models with interactions for $A P O E \varepsilon 4$ and ${ }^{18} \mathrm{~F}$-AV-1451 to predict cortical thickness (Fig. 3). There were significant interactions in the lateral parietal, medial parietal, and frontal regions, and in whole brain cortex $(P<0.05)$, indicating that the effects of ${ }^{18} \mathrm{~F}-\mathrm{AV}-1451$ on cortical thickness were more pronounced in $A P O E$ \&4-negative than in $A P O E$ $\varepsilon 4$-positive patients. The main effects of ${ }^{18} \mathrm{~F}-\mathrm{AV}$-1451 on cortical thickness were significant in $A P O E$ \&4-negative patients in all regions (except for the $\mathrm{E} / \mathrm{C}$ ratio), but only in lateral temporal and lateral parietal regions in $A P O E$ \&4-positive patients.

\section{Effects of APOE $\varepsilon 4$ and ${ }^{18} \mathrm{~F}-\mathrm{AV}$ - 1451 PET on cognition}

There were no significant interactions between $A P O E \varepsilon 4$ and (regional or global) ${ }^{18} \mathrm{~F}-\mathrm{AV}-1451$ to predict cognitive scores. We therefore only present models without interaction terms. $A P O E \varepsilon 4$ was a significant predictor of worse ADAS delayed recall, and better TMT-A, while greater (whole cortical) ${ }^{18} \mathrm{~F}$-AV-1451 signal was a significant predictor of worse animal fluency and (at trend level, $P=0.054$ ) worse MMSE (Table 3). We next included both APOE $\varepsilon 4$ and ${ }^{18} \mathrm{~F}-\mathrm{AV}-1451$ as predictors, which had minor effects on their respective separate estimates. The effect of ${ }^{18} \mathrm{~F}-\mathrm{AV}-1451$ on MMSE was $\beta=-3.838(P=0.054)$ before and $\beta=-4.024(P=0.046)$ after adjustment for $A P O E \varepsilon 4$, a difference of $4.9 \%$. Similarly, the effect of $A P O E \varepsilon 4$ positivity on ADAS delayed recall was $\beta=$ 2.124 $(P=0.01)$ before and $\beta=2.170(P=0.01)$ after adjustment for ${ }^{18} \mathrm{~F}-\mathrm{AV}-1451$, a difference of $2.2 \% . R^{2}$ for the

Table $2{ }^{18} \mathrm{~F}-\mathrm{AV}-1451$ PET and cortical thickness by APOE status

\begin{tabular}{|c|c|c|c|c|c|c|}
\hline \multirow[t]{2}{*}{ Region } & \multicolumn{2}{|c|}{$\begin{array}{l}\text { APOE } \varepsilon 4+ \\
\text { (unadjusted) }\end{array}$} & \multicolumn{2}{|c|}{$\begin{array}{l}\text { APOE } \varepsilon 4+ \\
\text { (adjusted for age and sex) }\end{array}$} & \multicolumn{2}{|c|}{$\begin{array}{l}\text { APOE } \varepsilon 4+ \\
\text { (adjusted for CSF Aß42) }\end{array}$} \\
\hline & $\beta$ & $P$ value & $\beta$ & $P$ value & $\beta$ & $P$ value \\
\hline \multicolumn{7}{|l|}{${ }^{18} \mathrm{~F}-\mathrm{AV}-1451$} \\
\hline Medial temporal & -0.039 & 0.561 & -0.011 & 0.873 & -0.047 & 0.467 \\
\hline Lateral temporal & -0.191 & 0.123 & -0.128 & 0.269 & -0.201 & 0.106 \\
\hline Lateral parietal & -0.343 & 0.024 & -0.238 & 0.067 & -0.37 & 0.013 \\
\hline Medial parietal & -0.349 & 0.015 & -0.252 & 0.044 & -0.364 & 0.011 \\
\hline Frontal & -0.175 & 0.092 & -0.088 & 0.305 & -0.193 & 0.054 \\
\hline Occipital & -0.221 & 0.04 & -0.187 & 0.073 & -0.228 & 0.035 \\
\hline Whole cortical & -0.203 & 0.041 & -0.134 & 0.12 & -0.219 & 0.024 \\
\hline ERC/cortex ratio & 0.123 & 0.049 & 0.105 & 0.078 & 0.128 & 0.041 \\
\hline \multicolumn{7}{|l|}{ Cortical thickness } \\
\hline Medial temporal & -0.022 & 0.787 & 0.01 & 0.899 & 0.015 & 0.875 \\
\hline Lateral temporal & 0.037 & 0.496 & 0.05 & 0.38 & 0.046 & 0.475 \\
\hline Lateral parietal & 0.101 & 0.014 & 0.097 & 0.017 & 0.111 & 0.024 \\
\hline Medial parietal & 0.116 & 0.002 & 0.113 & 0.002 & 0.125 & 0.004 \\
\hline Frontal & 0.056 & 0.137 & 0.057 & 0.144 & 0.065 & 0.137 \\
\hline Occipital & 0.042 & 0.188 & 0.05 & 0.128 & 0.055 & 0.141 \\
\hline Whole cortical & 0.057 & 0.104 & 0.063 & 0.083 & 0.07 & 0.093 \\
\hline ERC/cortex ratio & -0.090 & 0.102 & -0.062 & 0.205 & -0.096 & 0.085 \\
\hline
\end{tabular}

Effects of $A P O E$ \&4+ on ${ }^{18} \mathrm{~F}-\mathrm{AV}$-1451 (top part) and cortical thickness (lower part), in different linear regression models Significant results $(P<0.05)$ are indicated in bold The unadjusted effects correspond to Figs. 1 and 2 CSF cerebrospinal fluid, ERC entorhinal cortex 


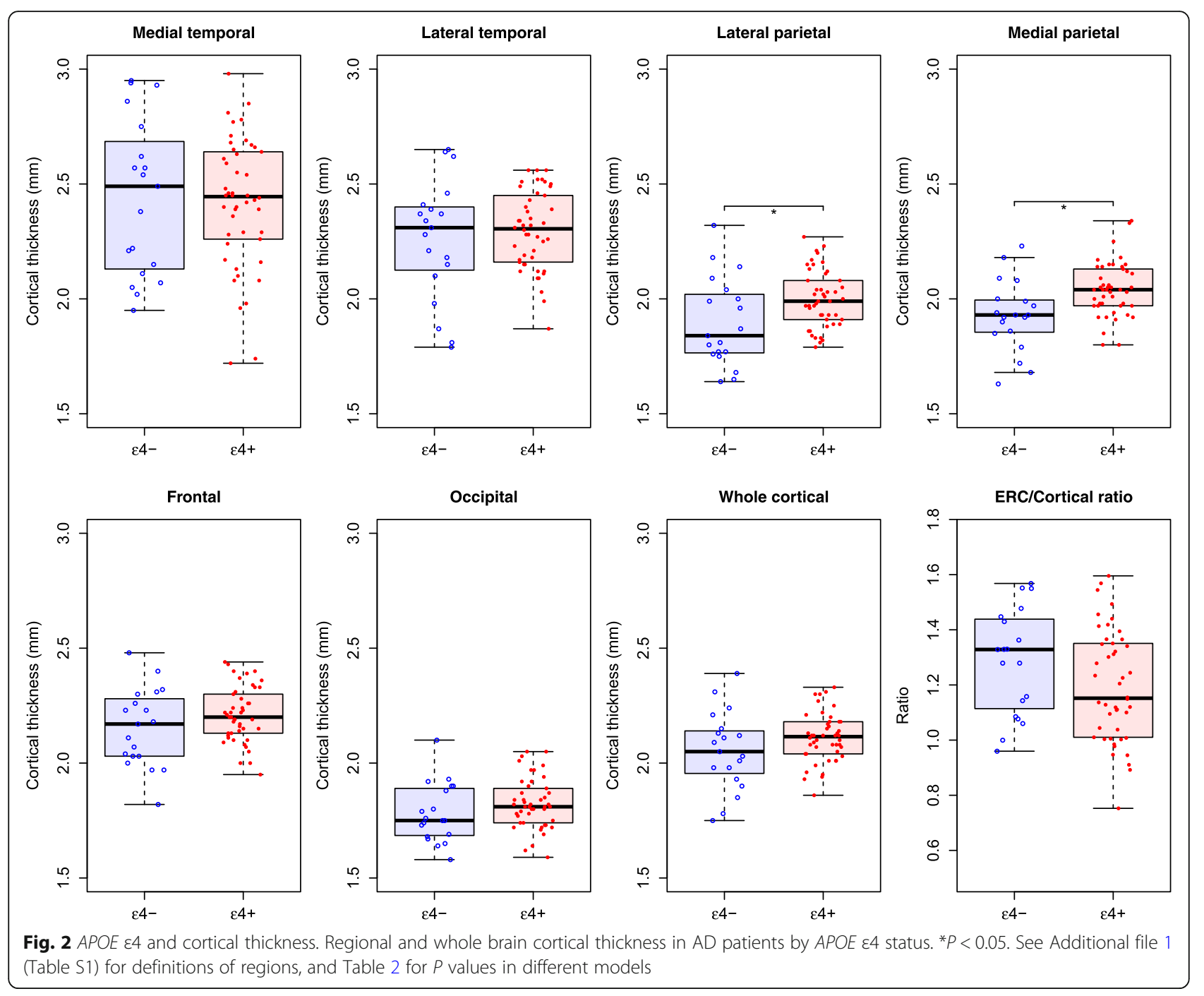

models was only minimally affected by combining the modalities, and comparisons of AIC never favored the combination of $A P O E \varepsilon 4$ and ${ }^{18} \mathrm{~F}-\mathrm{AV}-1451$ over the best individual model (Table 3). Taken together, this suggests that APOE \&4 and ${ }^{18} \mathrm{~F}-\mathrm{AV}-1451$ had independent effects on the cognitive measures.

These models used global cortical ${ }^{18} \mathrm{~F}-\mathrm{AV}-1451$, but the results for regional ${ }^{18} \mathrm{~F}-\mathrm{AV}-1451$ were very similar (data not shown). For TMT-A, the effect of ${ }^{18} \mathrm{~F}-\mathrm{AV}-1451$ was significant in occipital, lateral parietal, and lateral temporal regions, corresponding to the trend for global ${ }^{18} \mathrm{~F}-\mathrm{AV}-1451$ (Table 3).

\section{Effects of APOE $\varepsilon 4$ and ${ }^{18}$ F-AV-1451 PET on cognition, adjusted for cortical thickness}

For cognitive tests that were associated with $A P O E \quad \& 4$ (ADAS delayed recall and TMT-A) or ${ }^{18} \mathrm{~F}-\mathrm{AV}-1451$ (MMSE and animal fluency), we performed exploratory analyses with additional adjustments for brain structure.
The effects of ${ }^{18} \mathrm{~F}-\mathrm{AV}-1451$ on cognition were reduced when adjusting for cortical thickness. The association with MMSE was eliminated $(P=0.25)$ by adjusting for global cortical thickness (which had an independent significant effect; $\beta=12.1, P=0.015$ ). The effect on animal fluency was attenuated by adjusting for global cortical thickness $(P=0.055)$ and eliminated $(P=0.18)$ by adjusting for medial temporal lobe thickness (which had an independent significant effect; $\beta=6.81, P=0.027$ ).

The effects of $A P O E \& 4$ in this exploratory analysis were largely independent from cortical thickness. The effect on ADAS delayed recall was not affected by adjusting for global cortical thickness, and only marginally affected ( $\beta=1.74, P=0.024)$ by adjusting for medial temporal lobe cortical thickness (which had an independent significant effect; $\beta=-2.97, P=0.022$ ). The effect on ADAS delayed recall also remained $(\beta=1.94, P=0.013)$ when adjusting for hippocampal volume (which was not significantly associated with memory in this combined 


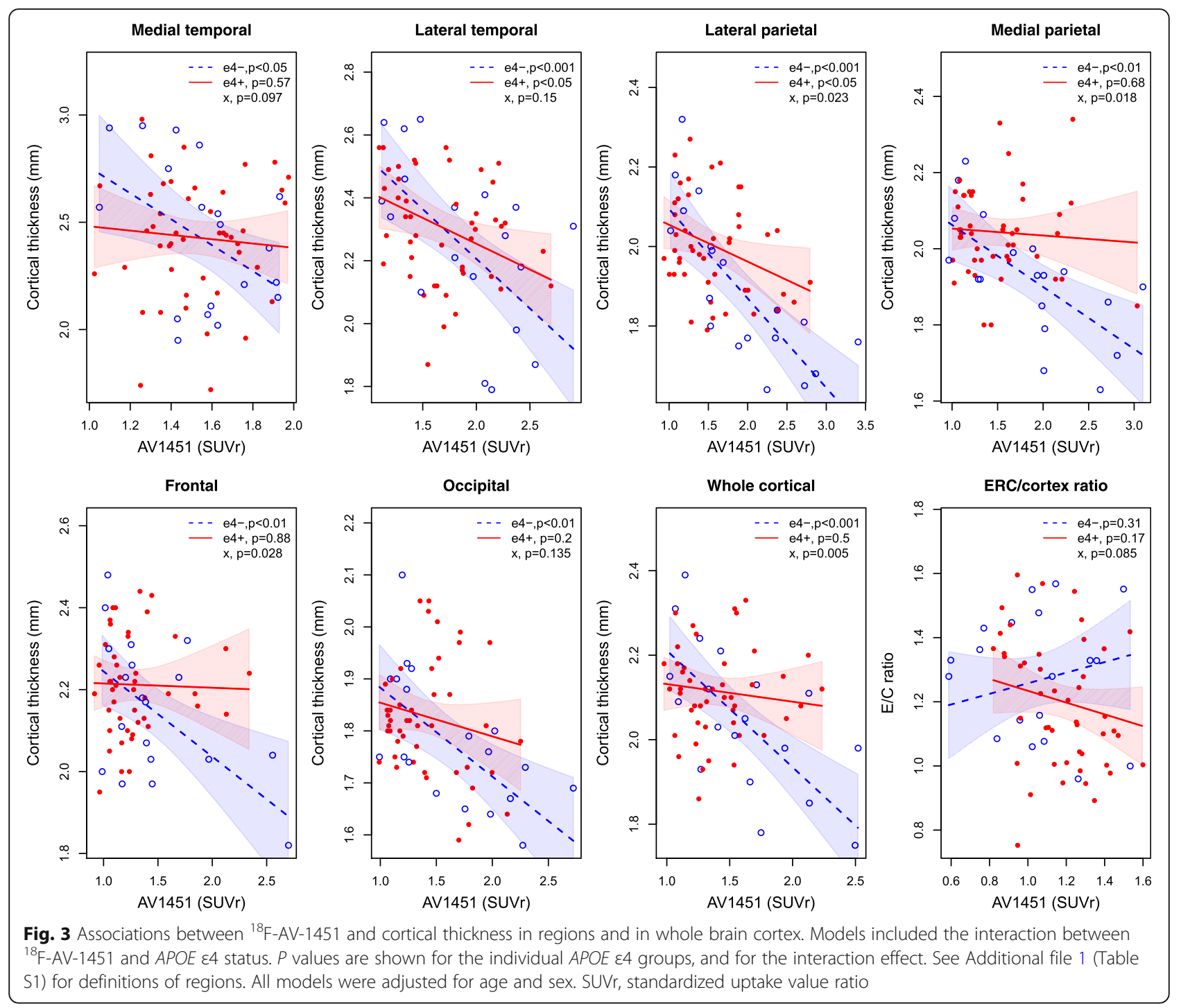

model; $\beta=-0.0013, P=0.079)$. For TMT-A, the effect was not affected by adjusting for global cortical thickness, and only marginally affected $(\beta=-55.2, P=0.0094)$ when adjusting for lateral temporal thickness (which had an independent significant effect; $\beta=-118, P=0.027$ ).

In summary, the effects of ${ }^{18} \mathrm{~F}-\mathrm{AV}-1451$ on cognition largely depended on cortical thickness, while the effects of $A P O E$ \&4 on cognition were largely independent of cortical thickness and hippocampal volume.

\section{Associations between ${ }^{18} \mathrm{~F}-\mathrm{AV}-1451$ and demographic factors}

Lower age was correlated with greater ${ }^{18} \mathrm{~F}-\mathrm{AV}$-1451 uptake. This was independent of $A P O E \varepsilon 4$ status, except in the medial temporal lobe where lower age was associated with ${ }^{18} \mathrm{~F}$-AV-1451 uptake in $A P O E$ \&4-positive but not in $A P O E \& 4$-negative patients (Fig. 4). There were no significant associations between sex and ${ }^{18} \mathrm{~F}-\mathrm{AV}-1451$, and no interactions between sex and $A P O E \& 4$ status to predict ${ }^{18} \mathrm{~F}-\mathrm{AV}-1451$ (data not shown).

\section{Associations between ${ }^{18} \mathrm{~F}$-flutemetamol and ${ }^{18} \mathrm{~F}-\mathrm{AV}$ - 1451}

There were no significant associations between ${ }^{18} \mathrm{~F}$-flutemetamol and ${ }^{18} \mathrm{~F}-\mathrm{AV}-1451$,

in either $A P O E$ \&4-positive or $A P O E$ \&4-negative patients (Additional file 1: Figure S4).

\section{Discussion}

$A P O E$ \&4-negative $\mathrm{AD}$ patients had increased ${ }^{18} \mathrm{~F}$-AV1451 (tau) uptake and reduced cortical thickness compared with $A P O E$ \&4-positive patients, particularly in the parietal cortex. In contrast, $A P O E$ \&4-positive patients had slightly higher uptake of ${ }^{18} \mathrm{~F}-\mathrm{AV}-1451$ in the entorhinal cortex relative to the whole cortex, and also had higher cortical ${ }^{18} \mathrm{~F}$-flutemetamol $(\mathrm{A} \beta)$ uptake. Regional associations between ${ }^{18} \mathrm{~F}-\mathrm{AV}-1451$ and cortical thickness 
Table 3 APOE \&4 and ${ }^{18} \mathrm{~F}-\mathrm{AV}-1451$ to predict cognition

\begin{tabular}{|c|c|c|c|c|c|}
\hline \multirow[t]{2}{*}{ Cognitive test } & \multirow[t]{2}{*}{ Predictors } & \multicolumn{2}{|l|}{$\beta$-coefficients } & \multirow[t]{2}{*}{$R^{2}$} & \multirow[t]{2}{*}{$\mathrm{AIC}$} \\
\hline & & $\overline{A P O E \varepsilon 4+}$ & ${ }^{18} \mathrm{~F}-\mathrm{AV}-1451$ & & \\
\hline \multirow[t]{3}{*}{ MMSE } & APOE ع4+ & $-0.581(P=0.67)$ & NA & 0.056 & 379.1 \\
\hline & ${ }^{18} \mathrm{~F}-\mathrm{AV}-1451$ & NA & $-3.838(P=0.054)$ & 0.112 & 375.2 \\
\hline & APOE $\varepsilon 4+$ and ${ }^{18} \mathrm{~F}-\mathrm{AV}-1451$ & $-0.946(P=0.48)$ & $-4.024(P=0.046)$ & 0.12 & 376.6 \\
\hline \multirow[t]{3}{*}{ ADAS immediate recall } & APOE ع4+ & $0.352(P=0.45)$ & NA & 0.091 & 211.7 \\
\hline & ${ }^{18} \mathrm{~F}-\mathrm{AV}-1451$ & NA & $0.968(P=0.14)$ & 0.118 & 209.9 \\
\hline & APOE $\varepsilon 4+$ and ${ }^{18} \mathrm{~F}-\mathrm{AV}-1451$ & $0.426(P=0.36)$ & $1.03(P=0.12)$ & 0.132 & 211 \\
\hline \multirow[t]{3}{*}{ ADAS delayed recall } & APOE ع4+ & $2.124(P=0.01)$ & NA & 0.168 & 260.9 \\
\hline & ${ }^{18} \mathrm{~F}-\mathrm{AV}-1451$ & NA & $1.724(P=0.13)$ & 0.086 & 266.3 \\
\hline & APOE $\varepsilon 4+$ and ${ }^{18} \mathrm{~F}-\mathrm{AV}-1451$ & $2.17(P=0.01)$ & $1.832(P=0.09)$ & 0.214 & 259.7 \\
\hline \multirow[t]{3}{*}{ TMT-A } & APOE ع4+ & $-47.961(P=0.03)$ & NA & 0.158 & 634.5 \\
\hline & ${ }^{18} \mathrm{~F}-\mathrm{AV}-1451$ & NA & $57.62(P=0.07)$ & 0.131 & 636.2 \\
\hline & APOE $\varepsilon 4+$ and ${ }^{18} \mathrm{~F}-\mathrm{AV}-1451$ & $-44.371(P=0.04)$ & $51.109(P=0.09)$ & 0.204 & 633.3 \\
\hline \multirow[t]{3}{*}{ Letter fluency (S) } & APOE ع4+ & $2.537(P=0.11)$ & NA & 0.167 & 327.1 \\
\hline & ${ }^{18} \mathrm{~F}-\mathrm{AV}-1451$ & NA & $-0.659(P=0.79)$ & 0.123 & 329.9 \\
\hline & $A P O E \varepsilon 4+$ and ${ }^{18} \mathrm{~F}-\mathrm{AV}-1451$ & $2.54(P=0.12)$ & $0.023(P=0.99)$ & 0.167 & 329.1 \\
\hline \multirow[t]{3}{*}{ Animal fluency } & APOE ع4+ & $1.969(P=0.27)$ & NA & 0.108 & 340.1 \\
\hline & ${ }^{18} \mathrm{~F}-\mathrm{AV}-1451$ & NA & $-6.637(P=0.01)$ & 0.198 & 334.4 \\
\hline & APOE $\varepsilon 4+$ and ${ }^{18} \mathrm{~F}-\mathrm{AV}-1451$ & $1.238(P=0.47)$ & $-6.304(P=0.02)$ & 0.207 & 335.8 \\
\hline \multirow[t]{3}{*}{ AQT-CF } & APOE ع4+ & $-9.364(P=0.47)$ & NA & 0.078 & 518.4 \\
\hline & ${ }^{18} \mathrm{~F}-\mathrm{AV}-1451$ & NA & $21.59(P=0.23)$ & 0.097 & 517.3 \\
\hline & APOE $\varepsilon 4+$ and ${ }^{18} \mathrm{~F}-\mathrm{AV}-1451$ & $-7.717(P=0.55)$ & $20.403(P=0.26)$ & 0.104 & 518.9 \\
\hline
\end{tabular}

Linear regression models predicting different cognitive tests. $\beta$-coefficients are on the original scales. For each test, models were evaluated with different predictors: APOE $\varepsilon 4,{ }^{18} \mathrm{~F}-\mathrm{AV}$-1451, or both APOE $\varepsilon 4$ and ${ }^{18} \mathrm{~F}-\mathrm{AV}$ - 1451 (no interactions). In all cases when APOE $\varepsilon 4$ or ${ }^{18} \mathrm{~F}-\mathrm{AV}$-1451were significant predictors alone, they remained significant with only minor changes in $\beta$-coefficients when adjusted for each other. All models were adjusted for age, sex and education. Comparisons of AIC never favored the combined models, since $\triangle \mathrm{AIC}$ ranged from -1.2 to 2 for the combined model minus the best (lowest AIC) individual model (a $\triangle \mathrm{AIC} \leq 2$ is generally not considered a meaningful model difference) Significant results $(P<0.05)$ are indicated in bold $A D A S$ Alzheimer's disease Assessment Scale, AIC Akaike information criterion, AQT-CF A Quick Test of cognitive speed-color and form, MMSE Mini-Mental State Examination, NA not applicable, TMT-A Trail Making Test-A

depended on $A P O E$ \&4 status, as greater ${ }^{18} \mathrm{~F}-\mathrm{AV}-1451$ uptake was associated with cortical thinning mainly in $A P O E$ \&4-negative patients. Both ${ }^{18} \mathrm{~F}-\mathrm{AV}$-1451 and $A P O E$ $\varepsilon 4$ were independently associated with cognition, but with different cognitive tests. These differences were found despite that age, sex, and global cognitive impairment not differing by $A P O E \& 4$ status. Taken together, these results suggest that $A P O E \varepsilon 4$ status influences differences in disease pathways, both through differential development and spread of tau pathology, and through effects on cognitive outcomes that may involve non-tau-related mechanisms. The proportion of $A P O E$ $\varepsilon 4$-negative patients was $29 \%$. This is in line with previous estimates of $A P O E \& 4$ prevalence in people with biomarker evidence of $\mathrm{A} \beta$ pathology, where $A P O E \varepsilon 4$ positivity is especially common in cohorts from northern Europe [43]. However, even at this relatively low frequency, the number of $\mathrm{AD}$ patients who are $A P O E \varepsilon 4$ negative will still be considerable in the population as a whole.
Our first main finding was that $A P O E$ \&4-negative patients had increased global ${ }^{18} \mathrm{~F}-\mathrm{AV}-1451$ uptake, with significant increases in the lateral parietal, medial parietal, and occipital areas. The APOE \&4-negative patients also had increased CSF T-tau and P-tau, which agrees with previous comparisons between ${ }^{18} \mathrm{~F}-\mathrm{AV}-1451$ and CSF tau [42, 44]. In contrast, APOE ع4-positive patients had higher relative ${ }^{18} \mathrm{~F}-\mathrm{AV}$ - 1451 uptake in the entorhinal cortex compared with the remaining cortex. Few studies have tested effects of $A P O E \varepsilon 4$ on tau PET imaging, but our results are consistent with a study in 62 (typical and atypical) $\mathrm{AD}$ patients, where the absence of $A P O E \varepsilon 4$ was associated with a greater ${ }^{18} \mathrm{~F}-\mathrm{AV}-1451$ signal in the neocortex and less signal in the entorhinal cortex (using a similar E/C ratio as here) [24]. A smaller study in 20 (mostly atypical) $\mathrm{AD}$ patients found that $A P O E \& 4$ was associated with greater ${ }^{18} \mathrm{~F}-\mathrm{AV}-1451$ signal in the bilateral medial temporal and right temporoparietal cortex [3]. Also, few studies have tested the effects of $A P O E \& 4$ 


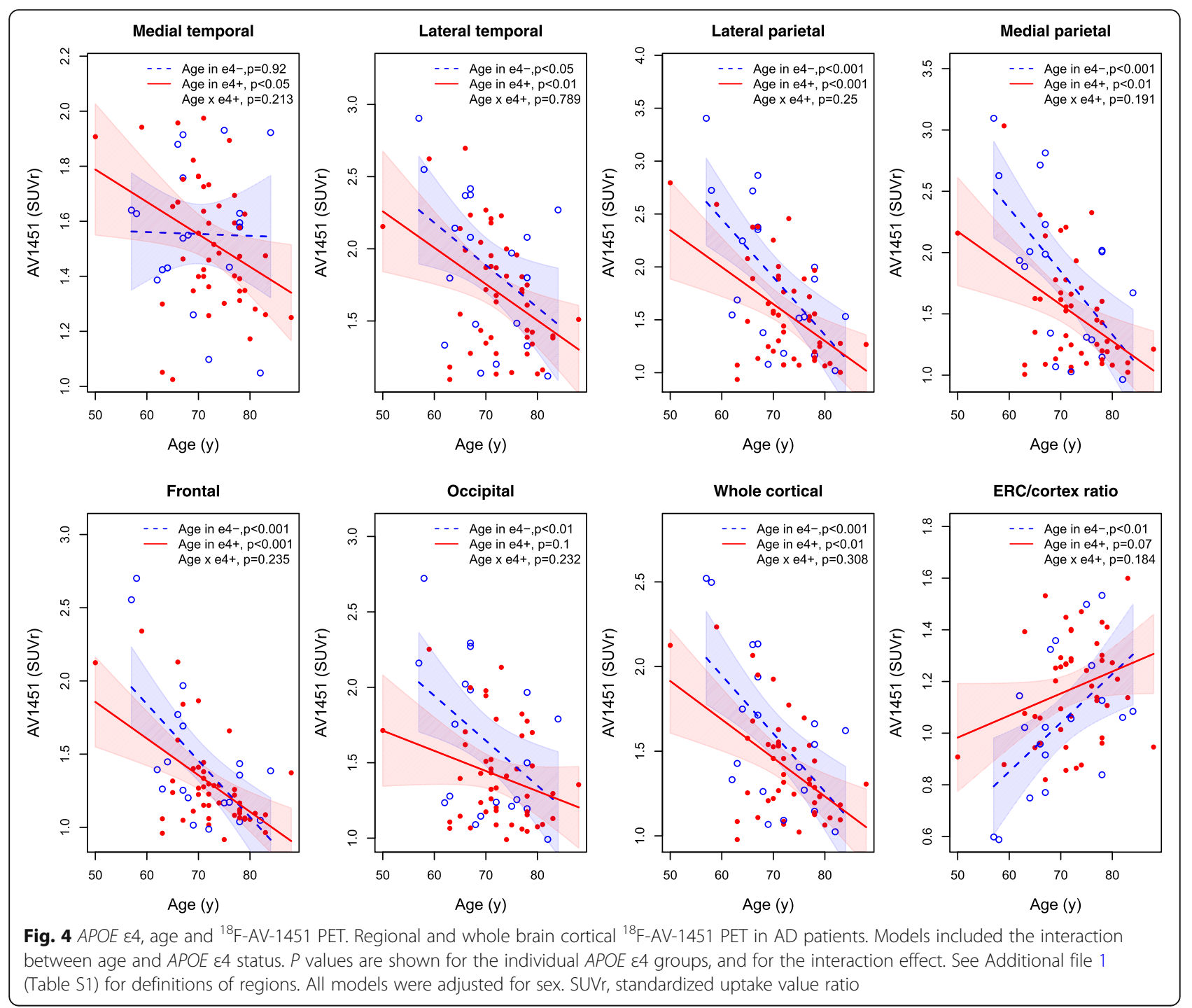

on CSF tau measures when restricting the analysis to people with biomarker evidence of $\mathrm{A} \beta$ pathology. Altmann et al. found increased CSF tau levels in $A P O E$ ع4-positive controls and MCI patients [45], but since that study also included people without biomarkers supporting $A \beta$ positivity the results are difficult to compare with our study.

Our second main finding was that $A P O E$ \&4-negative patients also had reduced thickness in the lateral and parietal areas (but there were no APOE \&4-dependent differences in hippocampal volumes). This partly agrees with results that $A P O E$ \&4-negative AD patients have less temporal lobe atrophy [12] and hypometabolism [46] but more frontoparietal atrophy $[11,13]$ compared with $A P O E$ \&4-positive patients. Furthermore, ${ }^{18} \mathrm{~F}-\mathrm{AV}-1451$ and $A P O E$ \&4 status interacted to predict cortical thickness, with stronger effects of ${ }^{18} \mathrm{~F}-\mathrm{AV}-1451$ on atrophy in
APOE \&4-negative patients. The interaction was mainly present in the parietal and frontal lobes.

Our results support a hypothetical model in which $A P O E$ \&4-dependent differences in patterns of atrophy are at least partly related to differences in the spread of tau pathology. One intriguing possibility is that the cortex, with frontoparietal regions in particular, is more vulnerable to tau in patients who develop $\mathrm{AD}$ despite lacking $A P O E \& 4$. The reason for this increased vulnerability is not clear. We considered the possibility that $A \beta$ pathology could contribute to the differences in atrophy and tau, but this is unlikely since the $A P O E$ \&4-positive patients had slightly greater $\mathrm{A} \beta$ load than the $A P O E$ $\varepsilon 4$-negative patients. Previous studies have found divergent results for associations between $A P O E \& 4$ and $A \beta$ in $\mathrm{AD}$, with either no effect of $A P O E \varepsilon 4$ on $\mathrm{A} \beta$ pathology [47], less $A \beta$ pathology $[46,48]$, or more $A \beta$ pathology 
[49] in $A P O E$ \&4-positive AD. Potentially, patients who develop AD despite lacking APOE $\varepsilon 4$ have other genetic abnormalities which put them at risk for degeneration [50]. Another possibility is that patients who develop $\mathrm{AD}$ and have an APOE \&4 allele may have partly non-tau-dependent cortical atrophy, perhaps due to impaired neuronal repair in the presence of $A P O E$ \&4 [51]. This may fit with the attenuated association between ${ }^{18} \mathrm{~F}-\mathrm{AV}-1451$ uptake and cortical thickness in $A P O E$ $\varepsilon 4$-positive patients in this study.

The remaining part of our study was on cognition. Due to the relatively small sample size and the inherent variability of cognitive measures, these results should be interpreted with caution and be regarded as preliminary. However, we reproduced known $A P O E$ $\varepsilon 4$-dependent profiles with relatively preserved memory function and more attention/processing speed impairment in $A P O E$ \&4-negative AD [11-14]. The fact that the associations between $A P O E \varepsilon 4$ status and delayed recall memory (worse in $A P O E$ \&4-positive) and TMT-A (worse in APOE e4-negative) remained significant when adjusting for ${ }^{18} \mathrm{~F}-\mathrm{AV}-1451$ or brain atrophy suggests that the relationship between $A P O E$ $\varepsilon 4$ status and cognition at least partly depends on non-tau-related mechanisms. In contrast, the associations between ${ }^{18} \mathrm{~F}-\mathrm{AV}-1451$ and cognitive tests were attenuated by adjusting for brain atrophy, which supports the hypothesis that tau accumulation leads to cognitive decline partly through atrophy [5].

Strengths of the study include the multimodal dataset, which combines brain MRI, tau and amyloid PET, CSF biomarkers, genetics, and cognitive data. Furthermore, the patients were recruited at a secondary referral clinic, which may make the sample more representative of the general $\mathrm{AD}$ population than samples recruited at more specialized centers. Another strength is that the APOE $\varepsilon 4$ groups were matched for age, sex, education, presence of dementia, and overall cognitive impairment (measured by MMSE). One limitation is the cross-sectional design. Longitudinal analyses are required to understand causal relationships between tau, atrophy, and cognition. For example, we cannot exclude the possibility of reverse causality for some of the associations, i.e., that $A P O E$ $\varepsilon 4$-negative patients had premorbid thinner cortices (especially in frontoparietal regions) which predisposed them to tau accumulation. In line with this, a study on neonates found that $A P O E \varepsilon 4$ carriers had reductions in volumes in temporal regions, but greater volumes in the parietal, frontal, and occipital cortex compared with $A P O E$ \&4-negative neonates, which suggests that some $A P O E$ ع4-dependent differences in brain structure (and perhaps vulnerability to tau) may already be present at birth [52] In the future, it will be informative to extend the current study with longitudinal data.

\section{Conclusions}

$A P O E \varepsilon 4$ status is associated with heterogeneity not only in clinical presentation and atrophy patterns in $\mathrm{AD}$, but also in the accumulation of tau pathology. $A P O E$ $\varepsilon 4$-negative patients may be more likely to deposit tau and have more atrophy in the parietal lobes compared with $A P O E$ \&4-positive $\mathrm{AD}$, which predispose them to a nonamnestic clinical phenotype.

\section{Additional file}

Additional file 1: Supplementary material. (DOCX 286 kb)

\section{Acknowledgements}

Doses of ${ }^{18} \mathrm{~F}$-flutemetamol injection were sponsored by GE Healthcare, and the precursor of ${ }^{18} \mathrm{~F}-\mathrm{AV} 1451$ was provided by AVID radiopharmaceuticals.

\section{Funding}

This study was supported by the European Research Council, the Swedish Research Council, the Marianne and Marcus Wallenberg foundation, the Strategic Research Area MultiPark (Multidisciplinary Research in Parkinson's disease) at Lund University, the Swedish Brain Foundation, the Skåne University Hospital Foundation, the Swedish Alzheimer Association, and the Swedish federal government under the ALF agreement.

\section{Availability of data and materials}

The dataset used during the current study is available from the corresponding author on reasonable request.

\section{Authors' contributions}

Drafting the manuscript: NM and RO. Revising the manuscript for content: all authors. Study concept or design: $\mathrm{NM}, \mathrm{RO}$, and $\mathrm{OH}$. Analysis or interpretation of data: NM, RO, and OH. Acquisition of data: SP, RS, ES, OS, TO, and JJ. Statistical analysis: NM and RO. Study supervision or coordination: $\mathrm{OH}$. Obtaining funding: $\mathrm{NM}$ and $\mathrm{OH}$. All authors read and approved the final manuscript.

\section{Ethics approval and consent to participate}

All participants gave written informed consent to participate in the study Ethical approval was given by the Ethical Committee of Lund University, Lund, Sweden, and all the methods were carried out in accordance with the approved guidelines. ${ }^{18}$ F-AV-1451 PET imaging approval was obtained from the Swedish Medicines and Products Agency and the local Radiation Safety Committee at Skåne University Hospital, Sweden.

Consent for publication

Not applicable.

\section{Competing interests}

$\mathrm{OH}$ has acquired research support (for the institution) from Roche, GE Healthcare, Biogen, AVID Radiopharmaceuticals, Fujirebio, and Euroimmun. In the past 2 years, he has received consultancy/speaker fees (paid to the institution) from Lilly, Roche, and Fujirebio. The remaining authors declare that they have no competing interests.

\section{Publisher's Note}

Springer Nature remains neutral with regard to jurisdictional claims in published maps and institutional affiliations.

\section{Author details}

${ }^{1}$ Clinical Memory Research Unit, Department of Clinical Sciences, Faculty of Medicine, Lund University, Lund, Sweden. ²Department of Neurology, Skåne University Hospital, Lund University, Lund, Sweden. ${ }^{3} \mathrm{VU}$ University Medical Center, Neuroscience Campus Amsterdam, Amsterdam, The Netherlands. ${ }^{4}$ Department of Radiation Physics, Skåne University Hospital, Lund, Sweden. ${ }^{5}$ Department of Clinical Physiology and Nuclear Medicine, Skåne University 
Hospital, Lund, Sweden. ${ }^{6}$ Memory Clinic, Skåne University Hospital, Malmö, Sweden

\section{Received: 21 March 2018 Accepted: 9 July 2018} Published online: 07 August 2018

\section{References}

1. Stopford CL, Snowden JS, Thompson JC, Neary D. Variability in cognitive presentation of Alzheimer's disease. Cortex. 2008:44:185-95.

2. Scheltens P, Blennow K, Breteler MMB, de Strooper B, Frisoni GB, Salloway S, et al. Alzheimer's disease. Lancet Lond Engl. 2016:388:505-17.

3. Ossenkoppele R, Schonhaut DR, Schöll M, Lockhart SN, Ayakta N, Baker SL, et al. Tau PET patterns mirror clinical and neuroanatomical variability in Alzheimer's disease. Brain J Neurol. 2016;139:1551-67.

4. Zhang X, Mormino EC, Sun N, Sperling RA, Sabuncu MR, Yeo BTT, et al. Bayesian model reveals latent atrophy factors with dissociable cognitive trajectories in Alzheimer's disease. Proc Natl Acad Sci U S A. 2016;113:E6535-44.

5. Bejanin A, Schonhaut DR, La Joie R, Kramer JH, Baker SL, Sosa N, et al. Tau pathology and neurodegeneration contribute to cognitive impairment in Alzheimer's disease. Brain J Neurol. 2017:140:3286-300.

6. Risacher SL, Anderson WH, Charil A, Castelluccio PF, Shcherbinin S, Saykin $\mathrm{AJ}$, et al. Alzheimer disease brain atrophy subtypes are associated with cognition and rate of decline. Neurology. 2017:89:2176-86.

7. Cummings JL. Cognitive and behavioral heterogeneity in Alzheimer's disease: seeking the neurobiological basis. Neurobiol Aging. 2000;21:845-61.

8. Corder EH, Saunders AM, Strittmatter WJ, Schmechel DE, Gaskell PC, Small GW, et al. Gene dose of apolipoprotein E type 4 allele and the risk of Alzheimer's disease in late onset families. Science. 1993;261:921-3.

9. Poirier J, Davignon J, Bouthillier D, Kogan S, Bertrand P, Gauthier S. Apolipoprotein E polymorphism and Alzheimer's disease. Lancet. 1993; 342:697-9.

10. Ward A, Crean S, Mercaldi CJ, Collins JM, Boyd D, Cook MN, et al. Prevalence of apolipoprotein E4 genotype and homozygotes (APOE e4/4) among patients diagnosed with Alzheimer's disease: a systematic review and metaanalysis. Neuroepidemiology. 2012;38:1-17.

11. Wolk DA, Dickerson BC. Alzheimer's Disease Neuroimaging Initiative. Apolipoprotein E (APOE) genotype has dissociable effects on memory and attentional-executive network function in Alzheimer's disease. Proc Natl Acad Sci U S A. 2010;107:10256-61.

12. Pievani M, Galluzzi S, Thompson PM, Rasser PE, Bonetti M, Frisoni GB. APOE4 is associated with greater atrophy of the hippocampal formation in Alzheimer's disease. Neurolmage. 2011;55:909-19.

13. van der Flier WM, Pijnenburg YA, Fox NC, Scheltens P. Early-onset versus late-onset Alzheimer's disease: the case of the missing APOE $\varepsilon 4$ allele. Lancet Neurol. 2011;10:280-8.

14. Ossenkoppele R, Cohn-Sheehy BI, La Joie R, Vogel JW, Möller C, Lehmann $M$, et al. Atrophy patterns in early clinical stages across distinct phenotypes of Alzheimer's disease. Hum Brain Mapp. 2015;36:4421-37.

15. Whitwell JL, Dickson DW, Murray ME, Weigand SD, Tosakulwong N, Senjem ML, et al. Neuroimaging correlates of pathologically defined subtypes of Alzheimer's disease: a case-control study. Lancet Neurol. 2012;11:868-77.

16. Hanseeuw BJ, Betensky RA, Schultz AP, Papp KV, Mormino EC, Sepulcre J, et al. Fluorodeoxyglucose metabolism associated with tau-amyloid interaction predicts memory decline. Ann Neurol. 2017;81:583-96.

17. LaPoint MR, Chhatwal JP, Sepulcre J, Johnson KA, Sperling RA, Schultz AP. The association between tau PET and retrospective cortical thinning in clinically normal elderly. Neurolmage. 2017;157:612-22.

18. laccarino L, Tammewar G, Ayakta N, Baker SL, Bejanin A, Boxer AL, et al. Local and distant relationships between amyloid, tau and neurodegeneration in Alzheimer's disease. Neuro Image Clin. 2018;17:452-64.

19. Nasrallah IM, Chen YJ, Hsieh M-K, Phillips JS, Ternes K, Stockbower GE, et al. 18 F-Flortaucipir PET/MRI correlations in nonamnestic and amnestic variants of Alzheimer disease. J Nucl Med Off Publ Soc Nucl Med. 2018:59:299-306.

20. Nelson PT, Alafuzoff I, Bigio EH, Bouras C, Braak H, Cairns NJ, et al. Correlation of Alzheimer disease neuropathologic changes with cognitive status: a review of the literature. J Neuropathol Exp Neurol. 2012;71:362-81.

21. Spires-Jones TL, Hyman BT. The intersection of amyloid Beta and tau at synapses in Alzheimer's disease. Neuron. 2014;82:756-71.

22. Farfel JM, Yu L, De Jager PL, Schneider JA, Bennett DA. Association of APOE with tau-tangle pathology with and without $\beta$-amyloid. Neurobiol Aging. 2016:37:19-25
23. Shi Y, Yamada K, Liddelow SA, Smith ST, Zhao L, Luo W, et al. ApoE4 markedly exacerbates tau-mediated neurodegeneration in a mouse model of tauopathy. Nature. 2017;549:523-7.

24. Whitwell JL, Graff-Radford J, Tosakulwong N, Weigand SD, Machulda M, Senjem ML, et al. [18 F]AV-1451 clustering of entorhinal and cortical uptake in Alzheimer's disease. Ann Neurol. 2018;83:248-57.

25. Palmqvist S, Zetterberg H, Mattsson N, Johansson P, Alzheimer's Disease Neuroimaging Initiative, Minthon L, et al. Detailed comparison of amyloid PET and CSF biomarkers for identifying early Alzheimer disease. Neurology. 2015;85:1240-9.

26. Petersen RC. Mild cognitive impairment as a diagnostic entity. J Intern Med. 2004:256:183-94.

27. McKhann GM, Knopman DS, Chertkow H, Hyman BT, Jack CR, Kawas CH, et al. The diagnosis of dementia due to Alzheimer's disease: recommendations from the National Institute on Aging-Alzheimer's association workgroups on diagnostic quidelines for Alzheimer's disease. Alzheimers Dement J Alzheimers Assoc. 2011;7:263-9.

28. Folstein MF, Folstein SE, McHugh PR. "Mini-mental state". A practical method for grading the cognitive state of patients for the clinician. J Psychiatr Res. 1975;12:189-98.

29. Rosen WG, Mohs RC, Davis KL. A new rating scale for Alzheimer's disease. Am J Psychiatry. 1984;141:1356-64.

30. Delis DC, Kaplan E, Kramer JH. Delis-Kaplan executive function system TM: Examiner's manual. San Antonio: The Psychological Corporation, A Harcourt Assessment Company; 2001.

31. Wiig EH, Annas P, Basun $H$, Andreasen $N$, Lannfelt L, Zetterberg $H$, et al. The stability of AQT processing speed, ADAS-Cog and MMSE during acetylcholinesterase inhibitor treatment in Alzheimer's disease. Acta Neurol Scand. 2010:121:186-93.

32. Blennow K, Hampel H, Weiner M, Zetterberg H. Cerebrospinal fluid and plasma biomarkers in Alzheimer disease. Nat Rev Neurol. 2010;6:131-44.

33. Palmqvist S, Zetterberg H, Blennow K, Vestberg S, Andreasson U, Brooks DJ, et al. Accuracy of brain amyloid detection in clinical practice using cerebrospinal fluid $\beta$-amyloid 42: a cross-validation study against amyloid positron emission tomography. JAMA Neurol. 2014;71:1282-9.

34. Sled JG, Zijdenbos AP, Evans AC. A nonparametric method for automatic correction of intensity nonuniformity in MRI data. IEEE Trans Med Imaging. 1998;17:87-97.

35. Dale AM, Fischl B, Sereno MI. Cortical surface-based analysis. I Segmentation and surface reconstruction. Neuroimage. 1999:9:179-94.

36. Fischl B, Dale AM. Measuring the thickness of the human cerebral cortex from magnetic resonance images. Proc Natl Acad Sci U S A. 2000;97:11050-5.

37. Fischl B, Salat DH, Busa E, Albert M, Dieterich M, Haselgrove $C$, et al. Whole brain segmentation: automated labeling of neuroanatomical structures in the human brain. Neuron. 2002;33:341-55.

38. Fischl B, Salat DH, van der Kouwe AJW, Makris N, Ségonne F, Quinn BT, et al. Sequence-independent segmentation of magnetic resonance images. Neurolmage. 2004:23(Suppl 1):S69-84

39. Schmidt P, Gaser C, Arsic M, Buck D, Förschler A, Berthele A, et al. An automated tool for detection of FLAIR-hyperintense white-matter lesions in multiple sclerosis. Neurolmage. 2012;59:3774-83.

40. Smith R, Schain M, Nilsson C, Strandberg O, Olsson T, Hägerström D, et al. Increased basal ganglia binding of (18) F-AV-1451 in patients with progressive supranuclear palsy. Mov Disord Off J Mov Disord Soc. 2017;32:108-14

41. Hahn A, Schain M, Erlandsson M, Sjölin P, James GM, Strandberg OT, et al. Modeling strategies for quantification of in vivo 18F-AV-1451 binding in patients with tau pathology. J Nucl Med Off Publ Soc Nucl Med. 2017;58:623-31.

42. Mattsson N, Smith R, Strandberg O, Palmqvist S, Schöll M, Insel PS, et al. Comparing 18F-AV-1451 with CSF t-tau and p-tau for diagnosis of Alzheimer disease. Neurology. 2018;90:e388-95.

43. Mattsson N, Groot C, Jansen WJ, Landau SM, Villemagne VL, Engelborghs S, et al. Prevalence of the apolipoprotein $E \varepsilon 4$ allele in amyloid $\beta$ positive subjects across the spectrum of Alzheimer's disease. Alzheimers Dement $J$ Alzheimers Assoc. 2018;14:913-24.

44. La Joie R, Bejanin A, Fagan AM, Ayakta N, Baker SL, Bourakova V, et al. Associations between [18F]AV1451 tau PET and CSF measures of tau pathology in a clinical sample. Neurology. 2018;90:e282-90.

45. Altmann A, Tian L, Henderson WW, Greicius MD. Sex modifies the APOErelated risk of developing Alzheimer's disease. Ann Neurol. 2014;75:563-73.

46. Lehmann M, Ghosh PM, Madison C, Karydas A, Coppola G, O'Neil JP, et al. Greater medial temporal hypometabolism and lower cortical amyloid burden in ApoE4-positive AD patients. J Neurol Neurosurg Psychiatry. 2014;85:266-73. 
47. Landen M, Thorsell A, Wallin A, Blennow K. The apolipoprotein E allele epsilon 4 does not correlate with the number of senile plaques or neurofibrillary tangles in patients with Alzheimer's disease. J Neurol Neurosurg Psychiatry. 1996;61:352-6.

48. Ossenkoppele R, van der Flier WM, Zwan MD, Adriaanse SF, Boellaard R, Windhorst AD, et al. Differential effect of APOE genotype on amyloid load and glucose metabolism in AD dementia. Neurology. 2013;80:359-65.

49. Drzezga A, Grimmer T, Henriksen G, Mühlau M, Perneczky R, Miederer I, et al. Effect of APOE genotype on amyloid plaque load and gray matter volume in Alzheimer disease. Neurology. 2009;72:1487-94.

50. Jiang S, Tang L, Zhao N, Yang W, Qiu Y, Chen H-Z. A systems view of the differences between APOE $\varepsilon 4$ carriers and non-carriers in Alzheimer's disease. Front Aging Neurosci. 2016;8:171.

51. Liu C-C, Kanekiyo T, Xu H, Bu G. Apolipoprotein E and Alzheimer disease: risk, mechanisms, and therapy. Nat Rev Neurol. 2013:9:106-18.

52. Knickmeyer RC, Wang J, Zhu H, Geng X, Woolson S, Hamer RM, et al. Common variants in psychiatric risk genes predict brain structure at birth. Cereb Cortex N Y N 1991. 2014;24:1230-46.

Ready to submit your research? Choose BMC and benefit from:

- fast, convenient online submission

- thorough peer review by experienced researchers in your field

- rapid publication on acceptance

- support for research data, including large and complex data types

- gold Open Access which fosters wider collaboration and increased citations

- maximum visibility for your research: over $100 \mathrm{M}$ website views per year

At $\mathrm{BMC}$, research is always in progress.

Learn more biomedcentral.com/submissions 